\title{
INTRA-ARTICULAR MORPHINE FOR PAIN RELIEF AFTER KNEE ARTHROSCOPY
}

\author{
G. P. JOSHI, S. M. MCCARROLL, C. M. COONEY, W. P. BLUNNIE, \\ T. M. O'BRIEN, A. J. LAWRENCE \\ From Cappagh Orthopaedic Hospital and Mater Misericordiae Hospital, Dublin
}

\begin{abstract}
We performed a randomised double-blind controlled study in patients undergoing elective knee arthroscopy to assess the effect of intra-articular morphine on postoperative pain relief. Patients in the study group $(n=10)$ received $5 \mathrm{mg}$ of morphine in a $25 \mathrm{ml}$ dilution intra-articularly while those in the control group $(n=10)$ received $25 \mathrm{ml}$ of saline. Postoperative pain was assessed at intervals by a visual analogue scale and the requirement for supplementary analgesia was recorded. Those in the study group had significantly lower pain scores and required less systemic analgesics than those in the control group.

Plasma profiles for morphine and its metabolites were assayed and showed that they were too low to produce effective analgesia. Evidence suggests that analgesia was mediated by local action within the joint.
\end{abstract}

Arthroscopy of the knee is frequently performed as daycase surgery. The degree of pain experienced after arthroscopy is very variable and seems to be unrelated to any intra-articular procedure which may be carried out. The ideal would be to provide patients with good local analgesia, of long duration and with no side-effects.

Intra-articular local anaesthetic agents are effective in relieving postoperative pain (Chirwa, MacLeod and Day 1989) but the duration of their effect is usually short and patients may need supplementary analgesia which delays their discharge. The presence of local opioid receptors in peripheral inflamed tissues has recently been reported and the possibility that analgesia may be achieved by local application of opioids has been raised (Stein et al 1988; Stein, Gramsch and Herz 1990). A recent publication has demonstrated effective postoperative analgesia with low doses of intra-articular morphine in patients undergoing knee arthroscopy (Stein et al 1991).

Our aim was to investigate the effect of intraarticular morphine on postoperative pain in patients

G. P. Joshi, MD, FFARCS I, Senior Research Associate

S. M. McCarroll, FFARCS I, Consultant Anaesthetist

C. M. Cooney, FFARCS I, Senior Research Associate

W. P. Blunnie, FFARCS I, Consultant Anaesthetist

Department of Anaesthesia and Intensive Care, Mater Misericordiae

Hospital and Cappagh Orthopaedic Hospital, Eccles Street, Dublin 7,

Republic of Ireland.

T. M. O'Brien, MCh, FRCS I, Professor of Orthopaedics

Cappagh Orthopaedic Hospital, Dublin, Republic of Ireland.

A. J. Lawrence, BSc, PhD, Senior Research Neurochemist

Pain Relief Foundation, Rice Lane, Liverpool L9 1AE, England.

Correspondence should be sent to Dr G. P. Joshi at the Department of Anaesthesiology, Oregon Health Sciences University, 3181 S.W. Sam Jackson Park Road, UHS-2, Portland, Oregon 97201-3098, USA.

(C) 1992 British Editorial Society of Bone and Joint Surgery $0301-620 X / 92 / 5433 \$ 2.00$

J Bone Joint Surg [Br] 1992; 74-B:749-51. undergoing knee arthroscopy and to study the mechanism of analgesia.

\section{PATIENTS AND METHODS}

The study was approved by our institute's ethical committee.

Twenty consecutive patients of ASA grade I or II (American Society of Anesthesiologists 1963) undergoing elective knee arthroscopy gave their informed consent and were included in the study. Before their premedication they were all instructed in the use of the $10 \mathrm{~cm}$ visual analogue scale (VAS), with zero and ten labelled respectively 'no pain' and 'worst pain imaginable'. Baseline pain scores were recorded and patients were premedicated with diazepam $0.15 \mathrm{mg} / \mathrm{kg}$ orally two hours pre-operatively.

A standardised protocol for general anaesthesia was followed. Anaesthesia was induced with a sleep dose of propofol (1.5 to $2 \mathrm{mg} / \mathrm{kg}$ ) and maintained with isoflurane in a mixture of $70 \%$ nitrous oxide in oxygen. Patients breathed spontaneously through a laryngeal mask airway. No narcotics were administered intra-operatively. Monitoring included a continuous electrocardiogram and non-invasive blood pressure, pulse oximetry and endtidal carbon dioxide measurements. At the conclusion of the arthroscopic procedure patients were allocated randomly into two groups. Those in the study group received $5 \mathrm{mg}$ of preservative-free morphine in a $25 \mathrm{ml}$ dilution, intra-articularly; those in the control group received $25 \mathrm{ml}$ of saline, intra-articularly. The tourniquet was kept inflated for ten minutes after the injection.

In the recovery room, after emergence from anaesthesia, an observer blind to the agent injected recorded the VAS at intervals of $0,0.5,1,1.5,2,4,8,12$, and 24 
hours after the operation. Patients who were asleep at any of these times had no VAS recorded for that interval. Patients who complained of pain while in the recovery room were given intravenous pethidine $(25 \mathrm{mg}$ every $5 \mathrm{~min}$ ) until the pain was controlled. On return to the surgical ward, supplementary analgesia (intramuscular pethidine $1 \mathrm{mg} / \mathrm{kg}$ ) was available on request. The severity (VAS) and the time of onset of pain were noted when analgesics were given. Each patient was interviewed 24 hours after the operation and the times and quantities of analgesics administered were recorded.

Venous blood samples were collected at $0.5,1,1.5$, 2 , and 4 hours after the intra-articular injection. Samples were aspirated into heparinised tubes from an indwelling 16-gauge cannula in the antecubital fossa. Plasma was separated immediately by centrifuge and then stored at $-20^{\circ} \mathrm{C}$ until analysed for morphine and its metabolites (morphine-3-glucuronide and morphine-6-glucuronide) using high-pressure liquid chromatography and native fluoroscence detection (Venn and Michalkiewicz 1990). The limit of detection was $1 \mathrm{ng} / \mathrm{ml}$ for all substances analysed.

The results are expressed as the mean \pm standard error of mean (SEM) and analysed using the paired Student's $t$-test. VAS of the two groups were compared using the Mann-Whitney $U$ test. A p value $<0.05$ was considered significant.

\section{RESULTS}

There was no significant difference between the two groups with regard to sex, age, height, weight and duration of anaesthesia (Table I), or in the baseline VAS.

The postoperative pain scores were significantly lower in the study group than in the control group ( $p<0.05$, Fig. 1) and their requirements for pethidine over the 24-hour study period was also significantly less (mean $15.0 \pm 7.64 \mathrm{mg}$ : mean $65.0 \pm 16.75 \mathrm{mg}$ : $\mathrm{p}<0.05$ ). The time interval before the first dose of

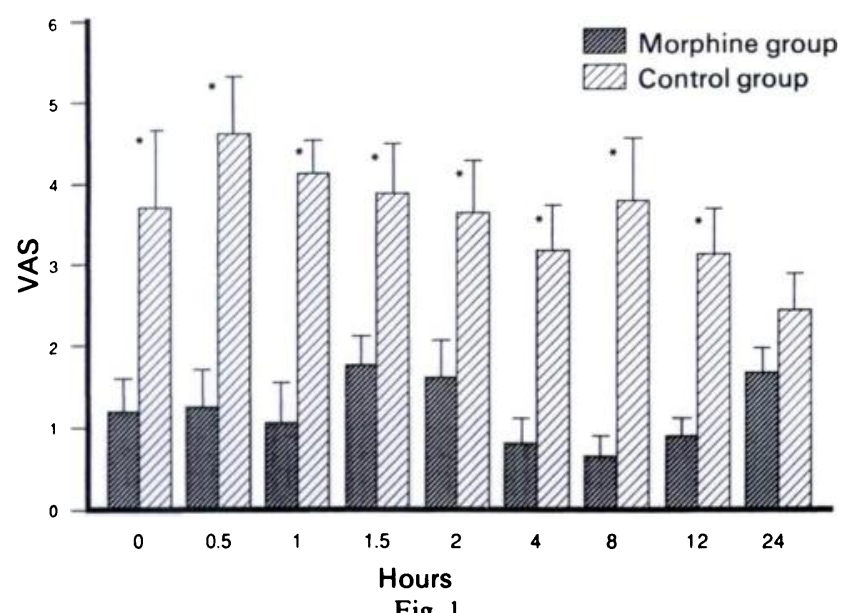

Visual analogue pain scores (mean \pm SEM) plotted against time, during the 24 hours after arthroscopy $\left({ }^{*}\right.$ indicates significantly higher VAS in the control group than in the morphine group). pethidine was required was significantly longer in the study group, and no patient in this group requested analgesia for the first 18 hours after the intra-articular injection.

The mean plasma concentrations of morphine and its primary metabolites, in eight out of the ten patients who received intra-articular morphine, are shown in Figure 2. They were below $10 \mathrm{ng} / \mathrm{ml}$ throughout the sampling period and three patients had no detectable morphine at any stage during the trial. The other two patients gave spurious results. In the first case the plasma level was $914.3 \mathrm{ng} / \mathrm{ml} 30$ minutes after injection with gradual clearance in the subsequent samples. In the second it was $470.8 \mathrm{ng} / \mathrm{ml}$ four hours after administration. The samples taken before and after this had no detectable morphine.

\section{DISCUSSION}

Intra-articular morphine provides effective analgesia for patients undergoing arthroscopy of the knee. The analgesia must be mediated at a local site of action within the joint since the plasma morphine levels were substantially lower than is necessary for postoperative pain relief. These results support the findings of Stein et al (1991).

The lower pain scores in the study group were associated with a much smaller requirement for systemic analgesics, reflecting the good pain relief produced by

Table I. Details of the two groups of patients who underwent arthroscopy (mean \pm standard error of the mean)

\begin{tabular}{lll}
\hline & $\begin{array}{l}\text { Morphine } \\
(\mathbf{n}=\mathbf{1 0})\end{array}$ & $\begin{array}{l}\text { Control } \\
(\mathbf{n}=10)\end{array}$ \\
\hline Male : Female & $8: 2$ & $7: 3$ \\
Age (yr) & $31.9 \pm 3.93$ & $31.6 \pm 3.87$ \\
Height (cm) & $170.75 \pm 2.32$ & $171.25 \pm 2.18$ \\
Weight (kg) & $76.1 \pm 3.43$ & $73.3 \pm 3.20$ \\
$\begin{array}{l}\text { Type of arthroscopy } \\
\text { Diagnostic/operative }\end{array}$ & $6 / 4$ & $6 / 4$ \\
Duration of anaesthesia (min) & $35.4 \pm 6.82$ & $39.4 \pm 4.42$ \\
\hline
\end{tabular}

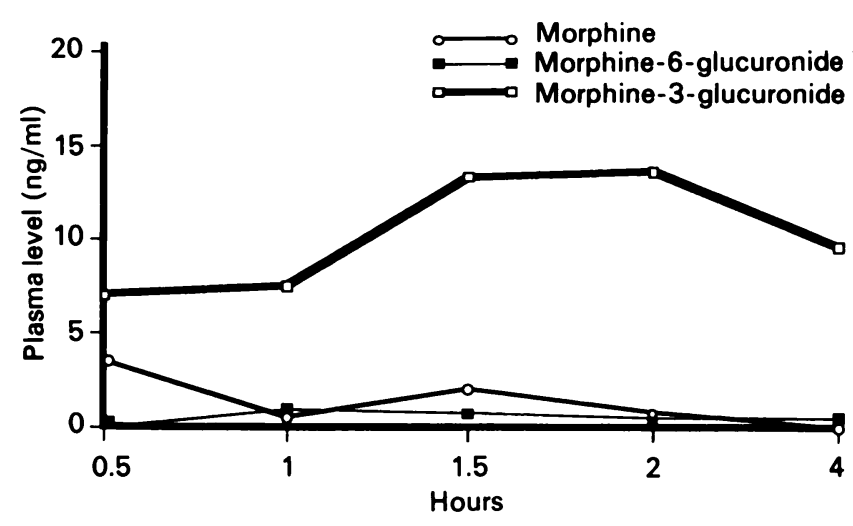

Fig. 2

Mean plasma levels of morphine and its major metabolites after administration of $5 \mathrm{mg}$ of intra-articular morphine. 
the intra-articular morphine. Another feature was its long duration. No patient in the study group required supplementary analgesia until 18 hours after the intraarticular injection and up to this time the quality of analgesia was better than in the control group.

An important aspect of the technique is the timing of the tourniquet release. The longer the time from intraarticular injection to tourniquet release the better is the local tissue binding of the drug. In pilot studies we found that the tourniquet needed to remain inflated for at least ten minutes after the morphine injection.

The second important factor is the dose and volume of the drug used. We decided on $5 \mathrm{mg}$ of morphine as this dose would not cause significant side-effects if it was all rapidly absorbed or inadvertently injected intravenously. The volume of $25 \mathrm{ml}$ was decided on as smaller volumes had proved ineffective and larger volumes were thought to be inappropriate after arthroscopy. Stein et al (1991) achieved effective analgesia using a smaller dose of morphine $(1 \mathrm{mg})$ in a $40 \mathrm{ml}$ dilution. They noted a delay, however, in the maximum effect for three to six hours after the injection whereas our patients experienced early onset of analgesia.

Eight of the ten patients had plasma morphine levels much lower than is generally accepted to be necessary for a systemic analgesic effect (Berkowitz et al 1975; Nayman 1979; Dahlström et al 1982). Of the two spurious results, one is consistent with a proportion of the morphine being injected intravenously rather than intraarticularly. Even so, after the first hour, the plasma levels were not sufficient to account for the long-lasting analgesia (18 hours) experienced by the patient. The second result suggests contamination during the sample collection.

The low plasma levels observed are not surprising since morphine is hydrophilic. Its poor lipid solubility would hamper its passage across the synovial membrane into the bloodstream and would increase the effective half-life of the drug. We only measured the levels of morphine and its metabolites in the plasma, but it would be interesting to see if glucuronidation occurred within the synovial cavity, with the production of active metabolites like morphine-6-glucuronide (Shimomura et al 1971; Osborne et al 1988), which would augment the analgesic effect. This might explain the prolonged period of pain relief obtained from a single $5 \mathrm{mg}$ injection.

Anti-nociceptive effects may be produced by at least two mechanisms. First, the action of morphine on the peripheral opiate receptors attenuates the excitability of the nociceptive input terminal. Secondly, the release of co-localised excitatory transmitters, such as substance $P$, from the peripheral endings of primary afferents may be inhibited. Stein et al $(1988,1990)$ have shown that opioid agonists induce anti-nociception via peripheral opioid receptors in inflamed tissue. There is as yet, however, no direct evidence that opioid receptors occur on neurones innervating the knee. The synovium is known to be innervated by peptidergic neurones, susceptible to substance P and CGRP (Konttinen et al 1990), and by noradrenergic neurones (Bjurholm et al 1990). Substance $P$ is the prime neuropeptide candidate for the role of transmitter in unmyelinated nociceptor afferents (Otsuka and Yanigisawa 1987). It would therefore be postulated that opioid receptors occur in the synovium either presynaptically or postsynaptically and act via an inhibitory feedback mechanism. Studies are currently under way to determine whether there are in fact opioid receptors in the synovium.

Conclusions. Intra-articular morphine provides effective and long-lasting pain relief after arthroscopy of the knee. The technique is simple and requires no special expertise or equipment. It is safe and should be free from sideeffects since the plasma morphine levels achieved are very low. The analgesia appears to result from local action within the joint.

The authors acknowledge financial support received from the Abbott Fund through the Education Subcommittee, Faculty of Anaesthetists, Royal College of Surgeons in Ireland and the Mater Foundation. They thank Mr Gargan, Chief Laboratory Technician, Cappagh Orthopaedic Hospital and Mr Michalkiewicz, Pain Relief Foundation, Liverpool and the Surgical and Theatre Staff of Cappagh Orthopaedic Hospital for their co-operation and support in making this study possible.

No benefits in any form have been received or will be received from a commercial party related directly or indirectly to the subject of this article.

\section{REFERENCES}

American Society of Anesthesiologists. New classification of physical status. Anesthesiology 1963; 24:111.

Berkowitz BA, Ngai SH, Yang JC, Hempstead J, Spector S. The disposition of morphine in surgical patients. Clin Pharmacol Ther $1975 ; 17: 629-35$

Bjurholm A, Kreicbergs A, Ahmed A, Schultzberg M. Noradrenergic and peptidergic nerves in the synovial membrane of the SpragueDawley rat. Arthritis Rheum 1990; 33:859-65.

Chirwa SS, MacLeod BA, Day B. Intraarticular bupivacaine (marcaine) after arthroscopic meniscectomy. Arthroscopy 1989; 5:33-5.

Dahlström B, Tamsen A, Paalzow L, Hartvig P. Patient-controlled analgesic therapy. Part IV: Pharmacokinetics and analgesic plasma concentrations of morphine. Clinical Pharmacokinetics $1982 ; 7: 266-79$.

Konttinen YT, Rees R, Hukkanen $\mathbf{M}$, et al. Nerves in inflammatory synovium: immunohistochemical observations on the adjuvant arthritic rat model. J Rheumatol 1990; 17:1586-91.

Nayman J. Measurement and control of postoperative pain. Ann R Coll Surg Engl 1979; 61:423-6.

Osborne R, Joel S, Trew D, Slevin M. Analgesic activity of morphine6-glucuronide. Lancet 1988; i:828.

Otsuka M, Yanagisawa $M$. Does substance $P$ act as a pain transmitter? Trends Pharmacol Sci 1987; 8:506-10.

Shimomura K, Kamata O, Ueki S, et al. Analgesic effect of morphine glucuronides. Tohoku J Exp Med 1971 ; $105: 45-52$.

Stein C, Millan MJ, Yassouridis A, Herz A. Antinociceptive effects of $\mu$ and $k$-agonists in inflammation are enhanced by a peripheral opioid receptor-specific mechanism. Eur J Pharmacol 1988; $155: 255-64$.

Stein C, Gramsch C, Herz A. Intrinsic mechanisms of antinociception in inflammation: local opioid receptors and beta-endorphin. $J$ Neurosci 1990; 10:1292-8.

Stein C, Comisel K, Haimerl E, et al. Analgesic effect of intra-articular morphine after arthroscopic knee surgery. New Engl J Med 1991; 325:1123-6.

Venn RF, Michalkjewicz. Fast reliable assay for morphine and its metabolites using high-performance liquid chromatography and native fluorescence detection. J Chromatogr 1990; 525:379-88. 